\title{
ПРОБЛЕМЫ УПРАВЛЕНИЯ АССОРТИМЕНТОМ В РОЗНИЧНОЙ ТОРГОВЛЕ В КОНТЕКСТЕ ОСОБЕННОСТЕЙ УСЛОВИЙ КОНКУРЕНЦИИ В ПОСТКРИЗИСНЫЙ ПЕРИОД
}

\author{
Н. Г. Новикова \\ Байкальский государственный университет, г. Иркутск, Российская Федерация
}

\author{
Информация о статье \\ Дата поступления \\ 14 марта 2018 г. \\ Дата принятия к печати \\ 21 мая 2018 г. \\ Дата онлайн-размещения \\ 8 июня 2018 г.

\section{Ключевые слова} \\ Торговые сети; особенности \\ условий конкуренции; \\ управление ассортиментом; \\ структуризация ассортимента; \\ уровень лояльности \\ потребителей
}

\begin{abstract}
Аннотация
Розничная торговля в России, пережившая серьезный спад во время экономического кризиса, выходит на новый, более высокий уровень конкуренции, который определяет необходимость не только повышения операционной эффективности торговых сетей, но и достижения и удержания лояльности целевых покупателей. В статье рассмотрено функционирование розничной торговли в условиях новой экономической реальности и выявлены особенности условий конкуренции в этой сфере, показано возрастающее значение управления ассортиментом как фактора обеспечения конкурентоспособности торговых сетей. Проанализированы различные подходы к пониманию процесса управления ассортиментом и разные методы его структуризации, выделено три группы методов структуризации ассортимента, описаны их достоинства и ограничения. Сорормулирован авторский подход к структуризации ассортимента, позволяющий отразить уровень лояльности целевых покупателей, показаны его преимущества и ограничения. Предложено два метода расчета показателя «уровень лояльности потребителей».
\end{abstract}

\section{ISSUES OF ASSORTMENT MANAGEMENT IN RETAIL TRADE WITHIN THE FRAMEWORK OF COMPETITION PECULIARITIES IN THE POST-CRISIS PERIOD}

\author{
Nadezhda G. Novikova \\ Baikal State University, Irkutsk, the Russian Federation
}

\section{Article info}

Received

March 14, 2018

Accepted

May 21, 2018

Available online

June 8, 2018

\section{Keywords}

Retail store networks: competition peculiarities; assortment management; assortment structuring; customers' loyalty level

\begin{abstract}
Retail trade in Russia, having weathered serious recession during the economic crisis, is moving to a new higher level of competition, which determines the need not only for efficiency improvement of store networks but also for gaining and retaining the target customers' loyalty. The article considers retail trade functioning in the conditions of the new economic reality and competition peculiarities in this sphere are revealed, a growing importance of assortment management as a factor of maintaining trade networks competitiveness is shown. Different approaches to understanding the process of assortment management and different methods of its structuring are analyzed, three groups of assortment structuring methods are singled out, their advantages and limitations are described. The author's approach to assortment structuring, which allows to reflect the level of the target customers' loyalty, is defined, its advantages and limitations are shown. Two methods of calculation of the index "customers' loyalty level» are offered.
\end{abstract}

Новая экономическая реальность в экономике России наложила заметный отпечаток на развитие розничной торговли и определила ряд особенностей условий конкуренции в этом секторе бизнеса. Под конкуренцией мы понимаем соперничество за лояльность и деньги целевых потребителей [1].

Данные особенности обусловлены совместным влиянием политических, экономических, технологических фракторов, которые 
стали причиной целого ряда проблем торговых организаций. При этом из числа решаемых наиболее острыми являются проблемы, связанные с управлением ассортиментом. Об их наличии в торговых сетях в какой-то мере свидетельствуют снижение оборота и его скорости, неликвидные, сверхнормативные товарные запасы и связанные с этим затраты и потери материальных, фринансовых ресурсов, необходимость проведения убыточных распродаж с целью получения денежных средств на обеспечение закупа товаров, потеря лояльности покупателей.

Изложенное определяет актуальность темы настоящей статьи, цель которой состоит в исследовании подходов к управлению ассортиментом, главным образом в части его структуризации в условиях появления ряда особенностей условий конкуренции в розничной торговле. Для достижения этой цели в статье поставлены и решены следующие задачи:

1. Рассмотреть изменения в сорере розничной торговли России, произошедшие в период экономического кризиса, и выделить особенности условий конкуренции.

2. Показать сущность логистического подхода к управлению ассортиментом.

3. Продемонстрировать значение структуризации ассортимента как основы процесса управления ассортиментом, систематизировать и рассмотреть ее варианты, предложить новый подход к структуризации ассортимента с учетом особенностей условий конкуренции на современном этапе развития розничной торговли в России.

По данным аналитиков, снижение розничного товарооборота за период 2015-2016 гг. составило около $20 \%{ }^{1}$. Несмотря на то что в середине 2017 г. Росстат зафиксировал незначительный рост оборотов розничной торговли ${ }^{2}$, который наблюдался ив последующие месяцы 2017 и 2018 гг., многие торговые сети были вынуждены уйти с рынка или значительно сократить свое присутствие на нем. Этот процесс коснулся не только торговых организаций и предприятий малого и среднего торгового бизнеса. Не справились с конкуренцией и некоторые крупные торговые сети, например “Седьмой континент», еще недавно занимавший 16-е место в рейтинге крупнейших частных компаний ${ }^{3}$.

${ }^{1}$ Тенденции развития розницы в 2017 году / / Retail. ru. URL: https: / / www.retail.ru/articles/141764.

2 Оборот розничной торговли // Федеральная служба государственной статистики : офиц. сайт. URL: http: / / www.gks.ru/wps/wcm/connect/rosstat main/ rosstat/ru/rates/55a8a2004a41fbc7bdd3bf78e6889fb6.

${ }^{3}$ Кто покинул российский рынок с начала 2017 года? // Retail.ru. URL: https://www.retail.ru/articles/144974.
В то же время некоторые торговые сети показали немалый рост. Здесь имеются в виду X5 Retail Group (сети «Пятерочка», «Перекресток», «Карусель») и «Магнит», лидирующие в сегменте быстро оборачивающихся товаров повседневного спроса (FMCG - fast moving consumer goods). Так, товарооборот X5 Retail Group за 2016 г. увеличился на $27 \%$. Такой рост был обеспечен в основном за счет открытия новых магазинов, число которых составило около 2 тыс. по всей стране. Всего же из общего числа открытых магазинов в России в кризисный период две трети приходится на долю X5 Retail Group и «Магнит» ${ }^{4}$. Условием выживания сегодня являются не только размеры ретейлера, но и умение управлять своей конкурентоспособностью, в том числе базируясь на научно обоснованных подходах к управлению ассортиментом. Авторская позиция по вопросам управления конкурентоспособностью в торговле представлена в [1].

Современный этап развития розничной торговли отличается присутствием двух противоречивых тенденций. С одной стороны, уровень монополизации торговли в центральных городах России достаточно высок и продолжает расти. По данным INFOLine, на топ-100 российского ретейла приходится треть всего розничного товарооборота. При этом десять игроков консолидировали больше половины выручки, приходящейся на топ-100, что составляет 4 трлн р. ${ }^{5}$ С другой стороны, в целом в стране существует множество мелких и средних торговых организаций и предприятий. Процесс сетезации в регионах только набирает обороты, поэтому еще одна особенность условий конкуренции заключается в экспансии федеральных торговых сетей на региональные рынки. Региональные сети, единственным конкурентным преимуществом которых зачастую выступает лучшая локация магазинов, сегодня имеют падение своих оборотов, уступая фредералам в ассортименте, ценах, современных торговых технологиях. Некоторые проблемы развития регионов были исследованы в [2].

Падение спроса населения, обусловленное проявлениями экономического кризиса и его последствий, представляет собой объективный фрактор снижения оборота розничной торговли для многих ретейлеров и также может быть отнесено к особенностям условий конкуренции.

${ }^{4}$ Тенденции развития розницы в 2017 году / / Retail. ru. URL: https: / / www.retail.ru/articles/141764.

${ }^{5}$ Там же. 
Стремительное развитие IT-технологий, которое меняет торговые процессы, тем самым влияя на конкурентоспособность внедривших их торговых организаций, является еще одной существенной особенностью условий конкуренции в розничной торговле России.

К числу наиболее перспективных IT-технологий для торговли специалисты относят биометрию, мобильные кассы, облачные решения, новые сервисы, например «1С-Товары», технологию Big Data, позволяющую создавать и обрабатывать большие массивы информации о потребителях. Ее внедрение позволит поднять на новый уровень работу по поиску путей повышения лояльности целевых покупателейб

Доступность новых торговых технологий определяется не только финансовой мощью торговых сетей, но и возможностью их покупки за рубежом. Сегодня многие федеральные торговые сети в числе своих миноритариев, в том числе и крупных, имеют зарубежные компании, что упрощает поиск и закупку перспективных торговых технологий за рубежом. Например, по данным ТАСС, американская инвестиционная компания Oppenheimer Funds Inc. является крупнейшим миноритарием торговой сети "Магнит» ${ }^{7}$.

Еще одно обстоятельство, вносящее коррективы в условия функционирования розничных сетей и, соответственно, в условия конкуренции, - изменения, внесенные в Федеральный закон «Об основах государственного регулирования торговой деятельности в Российской Федерации» (далее - Закон о торговле) от 28 декабря 2009 г. № 381-Ф3 в середине 2016 г. Так, прежние выплаты поставщиков ретейлерам, известные как ретробонусы и выплачиваемые с оборота товаров в размере $10 \%$, урезаны до $5 \%$. Теперь ретробонусы включают не только вознаграждение за приобретение определенного количества товаров, но и плату за оказание услуг по их продвижению, логистических услуг, услуг по подготовке, обработке, упаковке товаров, которые раньше оплачивались по договоренности сторон. Причем расчеты ретробонусов теперь должны вестись от «чистой» цены, т. е. без учета НДС и акцизов (ч. 4 ст. 9 Закона о торговле). Это нововведение при его выполнении в определенной мере снизит доходы торговых сетей

6 Революция в ритейле: технологии, меняющие бизнес // Retail.ru. URL: https://www.retail.ru/ articles /142600.

7 Торговая сеть «Магнит». Досье // ТАСС. 2018. 16 февр. URL: http://tass.ru/info/4965118. и повысит значение доходов от реализации ассортимента. Негативное влияние на доходы ретейла окажут и изменения, касающиеся сроков оплаты товаров с ограниченным сроком годности, а также увеличение размеров штрафов за нарушение закона.

Законодательно закрепленная обязательность использования онлайн-касс с июля 2017 г. явилась еще одним фрактором, повлиявшим на условия функционирования торговых организаций. По мнению аналитиков, за полгода работы онлайн-касс рынок «обелился» на 50 \%. До их введения наблюдаемый официальный оборот розничной торговли ежемесячно составлял немногим более 1 трлн р., после около 1,5 трлн ${ }^{8}$. Это существенным образом в массовом порядке ухудшило конкурентные позиции тех торговых сетей, которые сбывали «серый» товар, а также снизило доходы для тех, кто не платил налоги в полном объеме, занижая оборот.

Подводя итог рассмотрению особенностей условий конкуренции на современном этапе развития розничной торговли, можно сделать три основных вывода. Во-первых, вывод о том, что конкуренция усиливается, в том числе между фредеральными и региональными торговыми сетями. Во-вторых, условия для выживания малого и среднего торгового бизнеса, а также тех торговых предприятий и организаций, которые теряют своих покупателей из-за непонимания значения фрактора их лояльности, ухудшаются. В-третьих, сегодня главными условиями достижения конкурентоспособности являются операционная эффрективность и высокие объемы продаж. Последние возможны в значительной мере за счет высоких показателей лояльности целевых потребителей к торговой сети, ее ассортименту и ценам. Результаты исследования вопросов повышения, удержания лояльности покупателей в розничной торговле, подтверждающие ее растущее значение, представлены в [3-5]. Все это повышает значение обоснованности решений в процессе управления ассортиментом, что также, несомненно, является особенностью условий конкуренции на современном этапе развития розничной торговли.

Изучение подходов к пониманию сущности управления ассортиментом позволяет сделать вывод об отсутствии однозначности в понимании этого процесса теоретиками и практиками в области розничной торговли [6; 7]. В [7] нами было проведено исследование подходов к пониманию сущности процесса

8 Законодатели ибизнес: в поисках компромисса / / Retail.ru. URL: https://www.retail.ru/articles/147495. 
управления ассортиментом, обоснована правомерность логистического подхода и предложена его логическая модель, которая в своем уточненном виде представлена на рисунке.

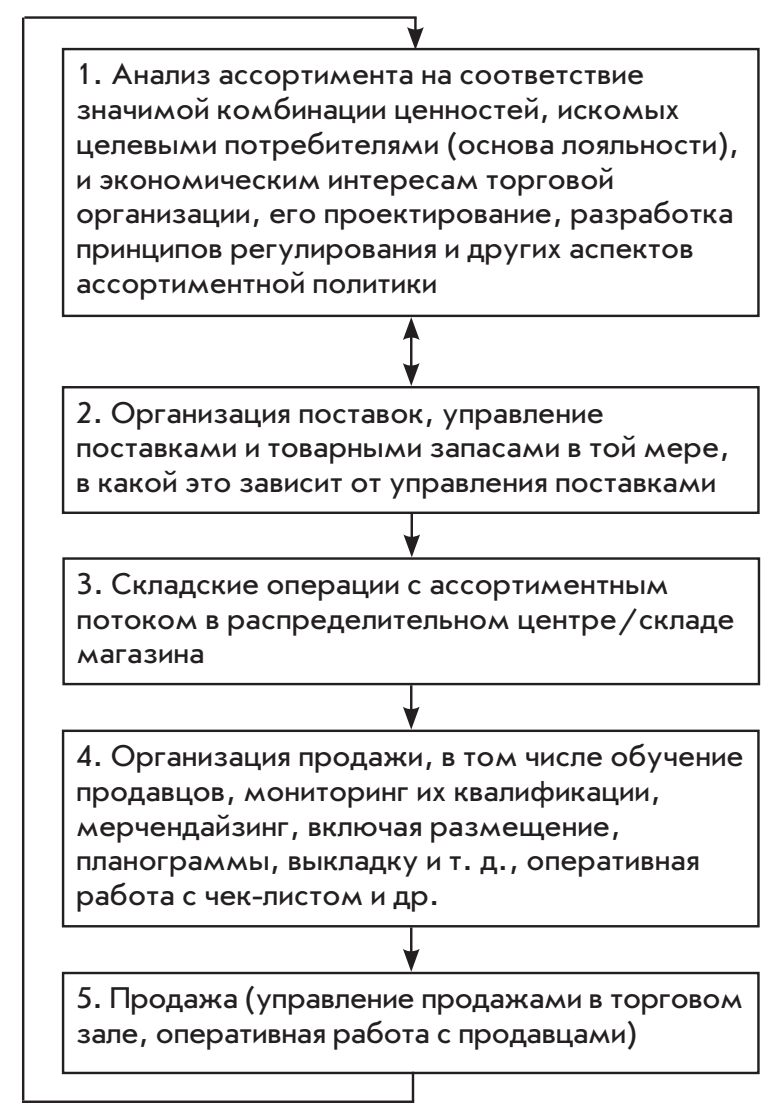

хода подтверждается тем, что в последние годы в специальной литературе появляются публикации, которые рассматривают вопросы управления ассортиментом за рамками этапа его анализа-проектирования [6; 8; 9].

Исследование этапов управления ассортиментом позволяет сделать вывод об особенном значении первого этапа, на котором принимаются решения о проектировании ассортимента, предшествующие формированию и движению материального и сопутствующих ему потоков. Свидетельством большого значения этого этапа является значительное количество семинаров, тренингов, проводимых сегодня известными специалистами в области управления ассортиментом, посвященных именно этому этапу управления ассортиментом9.

Сегодня продавцы программных решений по анализу ассортимента отрицают наличие проблем на этапе его анализа и проектирования, ссылаясь на то, что программные продукты все могут, все учитывают. Однако программный продукт содержит только те методологические подходы, которые в него заложены. Не все они позволяют получать достаточно обоснованные результаты. Не все они известны тем, кто ими пользуется. Это определяет необходимость изучения существующих, поиск и разработку новых, более обоснованных методологий в сфере управления ассортиментом, особое место среди которых принадлежит подходам к его стратегической структуризации, позволяющей объединять товарные категории в однородные группы, в то же время различающиеся между собой с позиции интересов продавца и покупателя.

Значение такой структуризации ассортимента определяется тем, что она позволяет видеть и отчетливо понимать, на чем мы зарабатываем деньги, а на чем их теряем, каковы перспективы развития товарных категорий, за счет чего можно поддерживать сбалансированный экономически выгодный ассортимент, приемлемый для торговой сети и фрормирующий значимую комбинацию ценностей, искомых целевыми покупателями.

Исследование подходов к структуризации ассортимента, представленных в специальной литературе, на специализированных сайтах, посвященных ретейлу, сайтах известных бизнес-тренеров и консалтинговых организаций по IT-решениям, позволило распределить все подходы к структуризации ассортимента на три большие группы.

\footnotetext{
9 Управление ассортиментом: категорийный менеджмент. М., 2018. URL: http://assorts.ru.
} 
К первой группе подходов, получивших наибольшее распространение в практике торговых сетей, мы отнесли АBC и XYZ виды анализа, возможность проводить которые заложена во все программные продукты, используемые торговыми сетями для учета и аналитики, в том числе и семейства 1 . АВС-анализ позволяет распределить все товарные позиции, категории на три группы по значимости на основании различных, актуальных по мнению специалистов критериев. Наиболее часто применяемыми критериями значимости являются товарооборот, маржинальность, прибыль, скорость оборота. XYZ-анализ также позволяет выделить три группы, однако по одному критерию - колеблемость. На его основе определяется степень стабильности спроса или степень стабильности поставок. Зачастую два вида анализа ( $A B C$ и XYZ) совмещаются, строится матрица из девяти квадрантов, по каждому из которых разрабатываются типовые решения по управлению ассортиментом. Проблемы и ограничения применения этих видов анализа были рассмотрены нами в [7]. В основном все они сводятся к необходимости иметь данные в динамике (что не всегда возможно) по всем анализируемым позициям, которые к тому же подвержены влиянию фрактора сезонности, а также других фракторов. Например, сменился поставщик, и вот уже товарная позиция, входившая в категорию «A», допустим, по объему продаж, входит В категорию «В», потому что не понравилась потребителям, стали меньше покупать. То же самое можно сказать и про сезонность. В то же время следует отметить, что на сегодняшний день $\mathrm{ABC}$ и XYZ виды анализа имеют больше достоинств, чем недостатков, и могут применяться при типизации товарных категорий при условии учета фракторов времени и сезонности.

Ко второй группе мы отнесли подходы, авторы которых выделяют роли для категорий, в рамках которых они объединяются в однородные группы, и для них также разрабатываются типовые решения. Этот подход расширяет наше понимание значения каждой категории в достижении значимых показателей и целей торговой организации. Рассмотрим несколько вариантов выделения ролей категорий. Вопросы выделения ролей категорий были исследованы в работах С. В. Балакирева, С. В. Сысоевой, Е. А. Бузуковой, А. А. Воронова, А. Р. Муратовой и др. [6; 10; 11]. В частности, С. В. Балакиревым был произведен анализ целого ряда подходов к выделению ролей, предложенных зарубежными авторами [10].

Так, J. Singh и R. Blattberg предлагают выделять четыре роли товарных категорий, которые получили названия «Предназначение», «Привилегированная», «Случайная/ceзонная», «Удобная». Специалисты компании Nielsen Marketing Research предлагают выделять также четыре роли товарных категорий: «Отражающие специализацию» (безалкогольные напитки, вино, фррэш), «Создатель трафика» (пиво, молочные продукты, консервы), «Обслуживание/сервисные» (бумага, кофе/чай), «Высокомаржинальные» (закуски, моющие средства, табак, соусы) [там же].

С. В. Балакирев предложил выделять семь ролей товарных категорий: «Создатель потока» (Traffic Builder), «Генератор наличности» (Cash Generator), «Генератор прибыли» (Profit Generator), «Создатель имиджа» (Image Creator), «Защитник» (Turf Defending), «Создатель желания» (Excitement Creating), "Стимулятор объема покупки» (Transaction Building) - среднего чека, «Тестовый товар или подкатегория»неосновная роль (Test SKU's) [там же].

С. В. Сысоева и Е. А. Бузукова выделяют пять ролей товарных категорий: «Уникальные» (1-3 \%), «Приоритетные» (алкоголь, мясная гастрономия, около 20 \%), «Базовые» (хлеб, молоко, йогурты, 40-50%), «Периодические (товары для диабетиков, владельцев животных и др.) и сезонные» (до 20 \%), «Удобные» (вспомогательные и сопутствующие) (10-15\%) [6].

Bсе эти авторы рассматривают каждую роль и рекомендуют целесообразные для нее управленческие решения и действия.

Исследование подходов к выделению ролей товарных категорий позволяет сделать следующие выводы:

1. Рассмотренные подходы сходны между собой пониманием того, что разные товарные категории играют различные роли с позиции таких целей розничной организации, как необходимость привлечь, заинтересовать, удержать покупателей с учетом сезонности спроса и на основе этого сделать оборот, заработать необходимую прибыль. При этом, по нашему мнению, подход, представленный С. В. Сысоевой и Е. А. Бузуковой, более рационален и полностью отражает основную идею структуризации ассортимента на основе ролей с учетом обозначенных выше целей торговой сети, в меньшей степени отличается размытостью границ между ролями. 
2. Все подходы в значительной степени сходны между собой в части того, что отражают различия между категориями с точки зрения покупателей. Однако только J. Singh и R. Blattberg рассматривают значение категорий с точки зрения интересов целевых покупателей. Последнее весьма важно в условиях особенностей конкуренции в розничной торговле России с позиции необходимости формирования лояльности целевых покупателей как важнейшего конкурентного преимущества.

3. Некоторые подходы содержат сведения о целесообразном процентном соотношении категорий с различными ролями. Так, С. В. Балакирев говорит о ролевой структуре ассортимента с позиции процентного соотношения их в суммарном количестве категорий торговой организации. Несколько более сложный подход предлагается в работе С. В. Сысоевой, Е. А. Бузуковой, которые, с одной стороны, говоря о соотношении ролей категорий в ассортименте, также имеют ввиду их долю в общем количестве товарных категорий [6, с. 284], с другой стороны, имеют ввиду их долю в объеме товарооборота (маржинальной прибыли) за период. Для определения того, какую роль играет категория в ассортименте, эти авторы рекомендуют проводить кросс-категориальный анализ, в котором за основу берутся данные по обороту и маржинальной прибыли [там же, с. 275].

4. Весьма важными с позиции практического управления ассортиментом являются рекомендации авторов по работе с каждой категорией, рассмотрение которых вышло за рамки настоящей статьи. Однако из этих рекомендаций следует, что многие авторы трактуют процесс управления ассортиментом шире, чем только комплекс решений по его анализу и проектированию.

5. Выделение ролей категорий, на наш взгляд, носит несколько произвольный характер, не всегда ясно, на основании каких конкретно критериев были определены те или иные роли. Это является причиной того, что распределение ролей категорий во всех рассмотренных подходах отличается некоторой субьективностью, которая снижается при проведении кросс-категориального анализа.

6. В целом изучение и применение ролевого подхода к структурированию категорий представляется актуальным в условиях современного этапа развития розничной торговли и особенностей условий конкуренции.

К третьей группе подходов мы отнесли подходы к структуризации ассортимента, основанные на идеологии матрицы БКГ (Бостонской консалтинговой группы, автор Брюс Д. Хендерсен), которые в последние годы в своем модифицированном для интересов розничной торговли виде разрабатывались многими исследователями [7; 10; 12]. Они предлагали структурировать товары, товарные группы и категории по разным парам критериев: прибыль и расширение спроса; темпы роста товарооборота и скорость оборота; темп роста товарооборота и уровень издержек и затрат; рост рыночной категории и доля рынка категории и др. Особенный интерес представляет подход Б. Харриса, представленный в [10], в котором сочетается модификация матрицы БКГ и ролевой подход. По нашему мнению, это снижает произвольность выделения ролей категорий.

Проведенное исследование подходов к структуризации ассортимента позволило сделать вывод об общем стремлении их авторов найти такое сочетание параметров для структуризации ассортимента, которое позволило бы получить надежный и понятный инструмент для его анализа, оценки, проектирования и дальнейшей работы, и предложить нам свой подход к решению проблемы структуризации ассортимента.

Суть предлагаемого нами подхода заключается в применении трех показателей для структуризации ассортимента. Это товарооборот, рентабельностьи уровень лояльности целевых покупателей. Показатели товарооборота и рентабельности позволяют оценить товарную категорию с позиции интересов торговой организации и косвенно - с позиции интересов покупателей. Показатель уровня лояльности потребителей к товарной категории дает возможность оценить ее с позиции интересов целевых потребителей, его высокое значение является фрактором стабильности/роста спроса, поэтому его введение в число показателей для структуризации ассортимента необходимо в контексте особенностей условий конкуренции в розничной торговле.

Методы определения границ обозначенных показателей, с ориентацией на которые товарные категории будут объединяться в однородные группы, могут быть различными. По нашему мнению, хорошим методом, принципы которого используются в матрице БКГ, является метод исчисления средних значений каждого применяемого показателя. В нашем случае это товарооборот, рентабельность, уровень лояльности. Их средние значения следует рассчитывать в целом для торговой сети из показателей, достигнутых 
каждой товарной категорией. Они и будут служить границами однородных групп товарных категорий, в которые последние будут объединяться по принципу «выше среднего / ниже среднего». В этом случае мы получим шесть однородных групп товарных категорий, различающихся между собой по степени выгодности для торговой сети и привлекательности для целевых покупателей. Этот вариант показан в матрице (табл.). Можно также применить и более детализированный вариант определения границ по показателям товарооборота и рентабельности на основе применения $\mathrm{ABC}$-анализа. По показателю уровня лояльности лучше оставить метод исчисления средних значений. Тогда мы получим 18 однородных групп. Возможны и другие варианты определения указанных границ в рамках предложенного нами подхода.

\begin{tabular}{|c|c|c|c|c|c|}
\hline \multicolumn{6}{|c|}{$\begin{array}{c}\text { Матрица для структуризации } \\
\text { товарных категорий }\end{array}$} \\
\hline & & \multicolumn{4}{|c|}{$\begin{array}{l}\text { Товарооборот } \\
\text { товарной категории }\end{array}$} \\
\hline & & \multicolumn{2}{|c|}{ Выше среднего } & \multicolumn{2}{|c|}{$\begin{array}{l}\text { Ниже } \\
\text { среднего }\end{array}$} \\
\hline & & \multicolumn{2}{|c|}{$\begin{array}{l}\text { Рентабель- } \\
\text { ность }\end{array}$} & \multicolumn{2}{|c|}{$\begin{array}{l}\text { Рентабель- } \\
\text { ность }\end{array}$} \\
\hline & & $\begin{array}{l}\text { Выше } \\
\text { сред- } \\
\text { него }\end{array}$ & $\begin{array}{l}\text { Ниже } \\
\text { сред- } \\
\text { него }\end{array}$ & $\begin{array}{l}\text { Выше } \\
\text { сред- } \\
\text { него }\end{array}$ & $\begin{array}{l}\text { Ниже } \\
\text { сред- } \\
\text { него }\end{array}$ \\
\hline \multirow{2}{*}{$\begin{array}{c}\text { Уро- } \\
\text { вень } \\
\text { лояль- } \\
\text { ности }\end{array}$} & $\begin{array}{c}\text { Выше } \\
\text { среднего }\end{array}$ & 1 & 2 & 3 & 4 \\
\hline & $\begin{array}{c}\text { Ниже } \\
\text { среднего }\end{array}$ & 5 & 6 & 7 & 8 \\
\hline
\end{tabular}

Распределение товарных категорий по группам (см. табл.) на основании предложенных показателей можно осуществить в три этапа. На первом этапе определяются значения товарооборота, рентабельности и уровня лояльности по каждой товарной категории за период. На втором рассчитываются средние значения каждого из этих трех показателей среди всех товарных категорий за тот же период. На третьем этапе товарные категории распределяются на однородные группы с учетом границ, в качестве которых используются средние значения предложенных показателей.

Очевидно, что самыми интересными для торговой организации и целевых потребителей одновременно являются группы категорий под номерами 1 и 2 (мы не стали присваивать группам ролевые названия, хотя это в принципе возможно). Они требуют постоянного внимания к наличию товарных запасов.

На втором месте находятся товарные категории, попавшие в группы с номерами 3 и 4.
Хотя товарооборот по ним ниже среднего по торговой организации, они имеют высокий уровень лояльности целевых потребителей и потому обеспечивают привлекательность магазинов торговой сети.

Товарные категории, попавшие в группыс номерами 5 и 6, очевидно находятся на грани снижения спроса. Они хотя еще и дают высокие показатели товарооборота с разной степенью рентабельности, однако уже утратили покупательскую лояльность. Возможно, это происходит из-за отсутствия конкурентов (оно всегда временно) или завершения жизненного цикла категории (тогда нужно готовиться к ее выводу из ассортимента) либо, возможно, из-за низкого качества товаров, несправедливых, по мнению покупателей, цен. В большинстве случаев необходимо работать в направлении повышения покупательской лояльности на основе установления более справедливых цен, предоставления скидок, изменения товарного наполнения категории, поиска новых поставщиков, новых марок товаров.

Особенное внимание следует уделить товарным категориям с номерами 7 и 8 . Они имеют не только низкий уровень покупательской лояльности, но и невысокие показатели товарооборота. Возможно, следует подумать об исключении их из ассортимента или поиске адекватных решений по их замене.

Для расчета показателей рентабельности могут быть использованы любые актуальные на конкретный момент их виды.

Принимая решения по развитию/сокращению, вводу/выводу товарных категорий, необходимо соблюдать баланс между объемом продаж высокорентабельных и низкорентабельных (в некоторых случаях даже убыточных) товарных категорий и позиций таким образом, чтобы запланированные показатели рентабельности в целом по торговой организации были достигнуты не в ущерб лояльности целевых покупателей. В тех случаях, когда совершенствование структуры ассортимента исчерпало свои возможности, поскольку она следует за структурой и объемом спроса, применяют различные варианты ценового выравнивания - сукцессивного и симультантного.

Для расчета показателя «уровень лояльности целевых потребителей» предлагается два варианта расчета.

Первый вариант. Уровень лояльности целевых покупателей рекомендуется определять на основании их опроса об удовлетворенности конкретными товарами и (или) товарными категориями. Причем опрос 
может проводиться как по всем позициям товарной категории, так и только по самым актуальным для торговой организации (последнее предпочтительнее). Такие опросы могут производиться как на сайте торговой организации, так и в торговом зале магазина по любой балльной шкале. Однако следует иметь ввиду, что для российских потребителей более понятной является пятибалльная шкала. При этом необходимо соблюдать два правила: респондентами должны быть покупатели целевых групп (методы их выявления и привлечения к опросам достаточно хорошо разработаны в практическом маркетинге); каждый респондент ставит свою оценку по каждой оцениваемой позиции в товарной категории. Особенно этот подход актуален при введении в ассортимент новых товарных категорий, развитии категорий. Идеология метода заключается в том, что все положительные оценки (для пятибалльной шкалы это 4 и 5) сопоставляются с максимально возможными оценками, отражающими полную удовлетворенность товарной позицией. Расчет рекомендуется производить по следующей формуле:

$$
L=\frac{\sum_{i}^{n} \sum_{j}^{m} O_{i j}}{O_{\max } \cdot n \cdot m},
$$

где $L$ - уровень лояльности целевых потребителей; $O_{i j}$ - оценка удовлетворенности по i-товарной позиции, данная j-м респондентом; $і$ изменяется от $1, n$, где $n-$ количество изучаемых товарных позиций, принадле- жащих изучаемой товарной категории; изменяется от $1, m$, где $m-$ количество респондентов; $O_{\max }$ - максимальная оценка по принятой для опроса шкале (по пятибалльной шкале это оценка 5).

Второй вариант. Уровень лояльности целевых покупателей может быть рассчитан путем отнесения товарооборота по дисконтным картам $\left(T_{d}\right)$ к общему товарообороту $(T)$ за тот же период по фрормуле $L=T_{d} / T$.

Достоинства и ограничения предложенного подхода к структуризации ассортимента:

1. Основан на применении наиболее важных показателей из числа характеризующих результаты управления ассортиментом, позволяющих одновременно оценить его выгодность для торговой организации и ценность для целевых покупателей. Это повышает обоснованность решений по управлению ассортиментом.

2. Дает возможность исключить произвольность в процессе структуризации ассортимента и определения ролей товарных категорий.

3. Не позволяет оценить изменения структурирующих показателей в динамике, поэтому в обязательном порядке при использовании матрицы требуется информация о прогнозах в отношении направлений и темпов изменения этих показателей.

4. Следует иметь в виду, что первый вариант для расчета показателя «уровень лояльности» дает некоторые погрешности, присущие использованию методов экспертных оценок на основе балльных шкал.

\section{СПИСОК ИСПОЛЬЗОВАННОЙ ЛИТЕРАТУРЫ}

1. Новикова Н. Г. Управление конкурентоспособностью коммерческой организации: маркетинговый подход : учеб. пособие / Н. Г. Новикова. - Иркутск : Изд-во БГУЭП, 2012. - 178 с.

2. Федотов А. Н. Механизм реализации стратегии развития региона с использованием концепции бенчмаркинга [Электронный ресурс] / А. Н. Федотов / / Baikal Research Journal. - 2016. - T. 7, № 4. - DOI: $10.17150 / 2411-6262.2016 .7(4) .12$.

3. Lavorata L. Influence of retailers' commitment to sustainable development on store image, consumer loyalty and consumer boycotts: Proposal for a model using the theory of planned behavior / L. Lavorata / Journal of Retailing and Consumer Services. - 2014. - Vol. 21, iss. 6. - P. 1021-1027.

4. Chen S.-C. Customer value and customer loyalty: Is competition a missing link?/ S.-C. Chen//Journal of Retailing and Consumer Services. - 2015. - Vol. 22. - P. 107-116.

5. Orel F.D. Supermarket self-checkout service quality, customer satisfaction, and loyalty: Empirical evidence from an emerging market/ F.D. Orel, A. Kara/ / Journal of Retailing and Consumer Services. - 2014. - Vol. 21, iss. 2. P. 118-129.

6. Сысоева С. В. Категорийный менеджмент. Курс управления ассортиментом в рознице / С. В. Сысоева, Е. А. Бузукова. - СПб. : Питер, 2015. - 400 с.

7. Новикова Н. Г. Логистический подход к управлению торговым ассортиментом и конкурентная стратегия розничной торговой организации [Электронный ресурс] / Н. Г. Новикова / / Известия Иркутской государственной экономической академии (Байкальский государственный университет экономики и права) (электронный научный журнал). - 2011. - № 5. - Режим доступа: http://brj-bguep.ru/reader/article.aspx?id=9709.

8. Каноян К. Анализ ассортимента «Инструменты розничного аналитика» [Электронный ресурс] / К. Каноян, Р. Каноян // Reaching Your Goals. - Режим доступа: http://www.stratomedia.com/retail-russian/retailarticles/assortment-management/assortment-analysis.htm. 
9. Каноян К. Управление ассортиментом: стратегия и тактика [Электронный ресурс] / К. Каноян, Р. Каноян // Reaching Your Goals. - Режим доступа: http://www.stratomedia.com/retail-russian/retail-articles/ assortment-management/assortment-strategy.htm.

10. Балакирев С. В. Маркетинговые классификации ролей товарных категорий / С. В. Балакирев / / Практический маркетинг. - 2011. - № 3. - С. 21-27.

11. Воронов А. А. Категорийный менеджмент (управление ассортиментом торговых предприятий) / А. А. Воронов, А. Р. Муратова. - Краснодар : Юг, 2015. - 140 с.

12. Николаева М. А. Товарная политика : учебник / М. А. Николаева. - М. : Норма, 2015. - 256 с.

\section{REFERENCES}

1. Novikova N. G. Upravlenie konkurentosposobnostyu kommercheskoi organizatsii: marketingovyi podkhod [Managing Competitiveness of a Commercial Organization: A Marketing Approach]. Irkutsk, Baikal State University of Economics and Law Publ., 2012. 178 p.

2. Fedotov A. N. Mechanism of implementing regional development strategy with the use of the concept of benchmarking. Baikal Research Journal, 2016, vol. 7, no. 4. DOI: 10.17150/2411-6262.2016.7(4).12. (In Russian).

3. Lavorata L. Influence of retailers' commitment to sustainable development on store image, consumer loyalty and consumer boycotts: Proposal for a model using the theory of planned behavior. Journal of Retailing and Consumer Services, 2014, vol. 21, iss. 6, pp. 1021-1027.

4. Chen S.-C. Customer value and customer loyalty: Is competition a missing link? Journal of Retailing and Consumer Services, 2015, vol. 22, pp. 107-116.

5. Orel F. D., Kara A. Supermarket self-checkout service quality, customer satisfaction, and loyalty: Empirical evidence from an emerging market. Journal of Retailing and Consumer Services, 2014, vol. 21, iss. 2, pp. 118-129.

6. Sysoeva S. V., Buzukova E. A. Kategoriinyi menedzhment. Kurs upravleniya assortimentom v roznitse [Category management. A course of assortment management in retail trade]. Saint Petersburg, Piter Publ., 2015. 400 p.

7. Novikova N. G. A logistics approach to trade assortment management and competitive strategies for retail companies. Izvestiya Irkutskoi gosudarstvennoi ekonomicheskoi akademii (Baykalskii gosudarstvennyi universitet ekonomiki i prava) = Izvestiya of Irkutsk State Economics Academy (Baikal State University of Economics and Law), 2011, no. 5. Available at: http://brj-bguep.ru/reader/article.aspx?id=9709. (In Russian).

8. Kanoyan K., Kanoyan R. Assortment Analyses «Retail Analyst Tools». Reaching Your Goals. Available at: http: / / www.stratomedia.com/retail-russian/retail-articles/assortment-management/assortment-analysis.htm. (In Russian).

9. Kanoyan K., Kanoyan R. Assortment Management: strategy and tactics. Reaching Your Goals. Available at: http: / / www.stratomedia.com/retail-russian/retail-articles/assortment-management/assortment-strategy.htm. (In Russian).

10. Balakirev S. V. Marketing Classifications of Product Categories Roles. Prakticheskii marketing $=$ Practical Marketing, 2011, no. 3, pp. 21-27. (In Russian).

11. Voronov A. A., Muratova A. R. Kategoriinyi menedzhment (upravlenie assortimentom torgovykh predpriyatii) [Category Management (Assortment Management of Commercial Enterprises)]. Krasnodar, Yug Publ., 2015. $140 \mathrm{p}$.

12. Nikolaeva M. A. Tovarnaya politika [Trade Policy]. Moscow, Norma Publ., 2015. 256 p.

\section{Информация об авторе}

Новикова Надежда Григорьевна - доктор экономических наук, профессор, кафедра логистики и коммерции, Байкальский государственный университет, 664003, г. Иркутск, ул. Ленина, 11, e-mail: ngn777@mail.ru.

\section{Для цитирования}

Новикова Н. Г. Проблемы управления ассортиментом в розничной торговле в контексте особенностей условий конкуренции в посткризисный период / Н. Г. Новикова // Известия Байкальского государственного университета. - 2018 . T. 28, № 2. - C. 257-265. - DOI: 10.17150/25002759.2018.28(2).257-265.

\section{Author}

Nadezhda G. Novikova - D.Sc. in Economics, Professor, Department of Logistics and Commerce, Baikal State University, 11 Lenin St. , 664003, Irkutsk, the Russian Federation, e-mail: ngn777@mail.ru.

\section{For citation}

Novikova N. G. Issues of Assortment Management in Retail Trade within the Framework of Competition Peculiarities in the Post-crisis Period. Izvestiya Baykal'skogo gosudarstvennogo universiteta = Bulletin of Baikal State University, 2018, vol. 28, no. 2, pp. 257-265. DOI: 10.17150/2500-2759. 2018.28(2).257-265. (In Russian). 